\begin{tabular}{|c|c|c|}
\hline $\begin{array}{l}\text { PKS } \\
\text { PUBLIC } \\
\text { KNDOLEDGE } \\
\text { PROJECT }\end{array}$ & $\begin{array}{c}\text { REVISTA DE GEOGRAFIA } \\
\text { (RECIFE) } \\
\text { http://www.revista.ufpe.br/revistageografia }\end{array}$ & 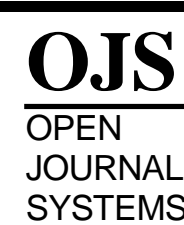 \\
\hline
\end{tabular}

\title{
CAMBIOS Y MANTENIMIENTOS EN EL MODELO AGRÍCOLA CUBANO
}

\author{
Antonielle Pinheiro da Cunha ${ }^{1}$
}

\begin{abstract}
${ }^{1}$ Doutorando do Programa de Pós-graduação em Geografia da Universidade Federal de Pernambuco. Professora de Geografia na Educação de Jovens e Adultos da Secretária de Educação de Pernambuco; Email: antoniellep@yahoo.com.br
\end{abstract}

Artigo recebido em 24/05/2016 e aceito em 15/03/2017

\begin{abstract}
RESUMO
A obra analisada traz elementos fundamentais para compreender as principais características da agricultura realizados após a Revolução. Igualmente, trata das mudanças recentes do modelo agrícola cubano e seu panorama frente aos novos Lineamentos da Política Econômica e Social do Partido e da Revolução aprovados no VI Congresso do Partido Comunista Cubano em abril de 2011. Apresenta um balanço histórico y atual, sobre a produção agrícola, os preços, as formas de comercialização, a propriedade da terra e o problema da dependência alimentar. $\mathrm{O}$ autor realiza um debate crítico frente às limitações da política agrícola cubana em promover o desenvolvimento das forças produtiva no setor agrícola. Fazendo com que as mudanças, como a entrega de terras ociosas, ainda não gerassem os resultados esperados. Realiza diálogos com experiências de mudanças na agricultura no Vietnã e sobre a produção de agrocombustíveis no Brasil. É um importante exemplar para se aproximar da realidade agrícola cubana e compreender as mudanças nas visões atuais sobre as relações entre mercado y planificação na economia socialista.
\end{abstract}

Palavras-chave: Dependência alimentar, mercado, propriedade da terra e planificação.

\section{CHANGES AND MAINTENANCE IN THE CUBAN AGRICULTURE MODEL}

\begin{abstract}
The work analyzed brings important elements to understand the principals characteristics of the agriculture made after the Revolution. At same time treat of the recent changes Cuban agriculture and your panorama front the news Lines of the Economic and Social Politic of Party and of Revolution approved in the VI Congress of Cuban Communist Party in April of e 2011. Presents a historical and actual balance about the agriculture production, the prices, the modes of commercialization, the propriety of land and the problem of alimentary dependency. The author realize a debate critic front the limitations of the Cuban agriculture politic to develop the productive forces in the agriculture sector. Making that the changes, like delivered of useless land, still don't generate the expected results. Realize dialogues with the experiences of changes in the agriculture of Vietnam and about de "agrocombutibles" production en Brazil. That is a important study to approximate of Cuban agriculture reality and understand the changes and the actuality visions about relations between market y planning in the socialist economy.
\end{abstract}

Keywords: Alimentary dependency, land propriety, market and planning. 


\section{INTRODUCCIÓN}

La agricultura cubana siguió por caminos distintos a lo largo del siglo XX y pasa en el actual siglo por cambios importantes para retomar de la producción agrícola a niveles superiores a los de antes de la crisis de los noventa. La obra "El modelo agrícola y los lineamentos de la política económica y social en Cuba", del doctor en economía Armando Nova González puntualiza elementos fundamentales para comprender los principales características de la agricultura asumidas después de la Revolución. Asimismo trata de los cambios recientes del modelo agrícola cubano y su panorama frente a los nuevos Lineamentos de la Política Económica y Social del Partido y La Revolución aprobados en el VI Congreso del Partido Comunista Cubano en abril de 2011.

Organizada en ocho capítulos, la obra presenta un balance histórico y actual sobre la producción agrícola, los precios, las formas de comercialización, la tenencia de tierras y el problema de la dependencia alimentaria. Todo el debate es acompañado de un minucioso trabajo con diversos datos estadísticos que ayudan a dimensionar los cambios analizados. Los capítulos, en general, están organizados de acuerdo con los períodos históricos: antes de la Revolución, el período revolucionario hasta los noventa, los años de crisis al final del siglo XX y la década de los años 2000 hasta 2011.

El autor realiza un debate crítico frente a las limitaciones de la política agrícola cubana para promover el desarrollo del las fuerzas productivas en el sector agrícola. Haciendo que cambios, como la entrega de tierras ociosas, aún no generen los resultados esperados. Además analiza experiencias de cambios de la agricultura en Vietnan y acerca de la producción de agrocombustibles en Brasil.

El libro es un importante ejemplar para acercase a la realidad agrícola cubana y comprender los cambios en las visiones actuales sobre las relaciones entre mercado y planificación en la economía socialista.

\section{CONSIDERACIONES SOBRE EL MODELO AGRÍCOLA CUBANO}

El primer capítulo "Producción de alimentos en Cuba" trata históricamente de este proceso y de la cuestión de la dependencia alimentaria. El problema alimentario cubano ya se presentaba antes de la etapa pre-revolucionaria. Como ejemplo de la inequidad en que se encontraba el campesinado cubano, según estudios realizados entre 1956 y 1957, el peso 
medio corporal del trabajador agrícola era de 16 libras por debajo del promedio nacional, solo el $4 \%$ consumía carne habitualmente. La vulnerabilidad económica y alimentaria se mostraba por la alta dependencia de importaciones, en un promedio anual de $1200 \mathrm{kcal}$ y 30,4 gramos de proteína, equivalentes al $47 \%$ y $53 \%$ del total disponible. Los Estados Unidos eran el principal suministrador, con $74 \%$ de las importaciones totales. La cuestión de la seguridad alimentaria e incrementos de la producción nacional fueron retos para la economía cubana a partir de 1959.

Entretanto, hasta finales de la década de los ochenta aún había una insuficiente producción nacional y un mantenimiento de la dependencia alimentaria, que es analizada a partir de varios datos del consumo diario de calorías y proteínas por habitante.

El volumen de importaciones de alimentos alcanzaban alrededor del 15\% del total de las importaciones. "La producción nacional de alimentos llegó a finales de la década de los ochenta a cubrir tan solo $28,1 \%$ y $39,7 \%$ del consumo total de calorías y proteínas, respectivamente". (GONZÁLEZ, p. 4). El destino económico de la tierra privilegiaba a los cultivos para la exportación.

Los años noventa son marcados por la agudización del problema de la disponibilidad alimentaria dada a la caída de la producción nacional y de condiciones para importación. Los análisis de tablas de consumo diario por nutrientes y de producción agrícola y ganadera entre 1989 y 2000 apuntan que la caída en el consumo de calorías per capita fue de 2845 kcal en 1989, hasta el nivel más bajo de 1853 kcal en 1994. La producción per cápita también disminuyó de forma significativa, a excepción del plátano. La merma de todos los reglones de la producción ganadera resultó en un bajo consumo de proteína de origen animal. El deterioro en la alimentación condujo a que se presentara graves problemas como la neuropatía epidémica, a partir de 1992 y 1993.

El período 2001-2010 fue marcado por la inestabilidad en la producción vegetal, con descenso a partir de 2004 y en la ganadería, principalmente vacuna. El aumento de las tierras ociosas, se manifiesta como un uso no eficiente de la tierra, acrecentado los bajos rendimientos agrícolas, serian señales de que las fuerzas productivas aún se encontraban detenidas.

En 2010 el sector registró 2,8\% de decrecimiento por reducción de producciones fundamentales. La superación de los niveles de alimentación anteriores al período de 1989 ocurrió debido a las importaciones de alimentos, incluso en niveles insostenibles como 2544 miles de dólares en 2008. 
La reducción de las importaciones en 2009, reflejada en la pequeña baja en el consumo de nutrientes en este año, fue debido a la falta de liquidez en divisa. Además, hubo un incremento en los precios de los alimentos motivado por la ocurrencia de ciclones a finales de 2008 .

Las tablas y datos presentados son importantes para conocer el escenario de la producción alimentaria antes y posteriormente al período de crisis. Estos apuntan al incremento de la vulnerabilidad alimentaria, una vez que el aumento del componente importado en la dieta se mantuvo durante el período, incluso a niveles más altos que en los años 50.

El segundo capítulo "Comercialización y precios de los productos agrícolas" puede ser considerado el más complejo de la obra por tratar de los diversos cambios ocurridos en el sistema de comercialización y acopio en la fase revolucionaria. Siendo fundamental para comprender las dificultades que se allan en el proceso de distribución de los alimentos.

El autor apunta la cuestión de la complejidad de la cadena agroproductivacomercializadora dentro de la economía cubana, estructurada por diversos subsistemas que se interactúan. Dicha cadena debería ser tratada bajo un enfoque sistémico.

La organización de la comercialización antes de 1959 tenía un carácter privado y mercantil. La producción de consumo directo o productos para la industrialización como caña, leche, café, azúcar, arroz, tabaco, ganado eran comercializados por intermediarios. No obstante con las tentativas del Estado de establecer precios mínimos fijos, a través administraciones de "Estabilización de precios" y de "Compra y venta", el peso del sector intermediario hizo que tales medidas no alcanzasen efectividad practica para muchos producto. Se mantuvieron las condiciones de explotación sobre el productor rural y la sociedad rural mayoritaria, resultando en falta de estimulo a las fuentes creadoras.

Paralela a la actuación del Ministerio de la Agricultura existían organizaciones paraestatales sectoriales compuestas por miembros del gobierno, productores y comercializadores, responsables por la estabilización de precios y definición de cuotas de producción, exportación, insumos, etcétera. La principal de estas fue el Instituto Cubano de Estabilización del Azúcar (ICEA), fundado en 1931.

Otras producciones como ganadería, papa, café, tabaco y arroz también eran reguladas por instituciones paraestatales similares, las cuales, destaca el autor, tuvieran un papel importante en la estabilización de precios. Y cita "desempeñaron un papel importante dentro de las relaciones capitalistas imperantes y en la implementación de mecanismos 
compensatorios respecto a las insuficiencias del mercado". (GONZÁLEZ, 2013, p.24). En La Habana la comercialización partía de dos grandes mercados concentradores: el Mercado Único y el Mercado del Vapor.

El período después de 1959 fue marcado por los constantes cambios en las formas de comercialización. Entre 1960 y 1988, o sea, en 28 años, se identificó cerca de nueve períodos generales de reestructuraciones en el sector de acopio y comercialización.

A partir de 1960 se inician procesos de nacionalización de la actividad de acopio y comercialización de acuerdo con las resoluciones del Instituto Nacional de Reforma Agraria (INRA), orientando un sistema empresarial especializado en acopio, beneficio y distribución de la producción mayorista. Entre 1961 y 1962 este sistema se organizó por un Departamento de Comercialización (disuelto en junio de 1962).

En 1962 se creó el Departamento de Acopios de Productos Agropecuarios, con nueve empresas nacionales subordinadas. Toda la producción era comprada a precios y normas fijas, control totalmente estatal de la comercialización y mayor control de la producción privada.

En 1963 con la Segunda Ley de Reforma Agraria hubo disolución de toda forma de comercialización privada. Entre 1963 y 1965 fueron disueltas las Empresas Nacionales de Acopio y se integra el acopio y el beneficio a la dirección de un Viceministerio de Acopio y las Empresas Provinciales de Acopio. Estas últimas enviaban el conjunto diverso de producciones a centros, subcentros y puntos de abastos en las grandes ciudades. Esta fue una forma más descentralizada y racional para el uso de recursos para la comercialización.

Entre 1965 y 1968 la organización de acopio y beneficio asume la atención y aseguramiento de la producción privada, captando más a esta producción.

Entre 1968 y 1970 hubo diversos cambios en relación a la atención al sector privado; los transportes; algunas cadenas de alimentos pasaran al Ministerio de la Industria Alimenticia (MINAL) y fueron dispensados personal de visitación. Todos los cambios en este periodo intentaban garantizar la llegada de productos a las empresas de beneficio o transformación. Entretanto, “también significó la separación o ruptura evidente de algunas cadenas agroproductivas-transportación-beneficio-industria, al quedar actividades continuas en diferentes organizaciones ministeriales" (GONZÁLEZ, 2013, p.29) o marcados por nuevas formas de centralización, como el paso de transporte de acopio a las Empresas Provinciales de Transporte Agropecuario. 
En 1970 son retomadas algunas formas modificadas en el período anterior, con creación del Grupo Nacional de Acopio (semejante a lo que era el Viceministerio de Acopio), Grupos Provinciales de Acopio y en 1972 reorganización de las empresas Provinciales de Acopio. Se retoma el transporte en 1973. Se reincorpora la Empresa Nacional de Frigoríficos. Se recupera el personal especializado en acopio, entre otros. Tales medidas permitieron la recuperación de la actividad, "pero sin la prioridad y centralización que esta había logrado en los primeros años del período anterior.” (GONZÁLEZ, 2013, p.30)

En 1976 la implantación del Sistema de Dirección y Planificación de la Economía (SDPE) traspasó 14 Empresas Provinciales de Acopio, la Empresa Comercializadora de Flores y la Empresa de Frigoríficos a subordinación de los órganos del poder popular y bajo la dirección estatal del Ministerio de Comercio Interior (MINCIN). Trayendo consecuencias como: distanciamiento de los productores de la comercialización; separación de la producción y el acopio de una organización sistémica; limitaciones para evaluaciones por parte del MINAGRI sobre la producción; falta de coherencia una vez que la empresa de acopio de La Habana se quedó dentro del sector agropecuario, MINAGRI. El sector agropecuario (MINAGRI) permaneció con la producción más especializada como: café, tabaco, frutas selectas, cítricos, huevo y miel. La comercialización y acopio de viandas, hortalizas y granos quedó bajo producción del MINCIN.

Entre 1981-1986 hubo se crearon de los Complejos Agroindustriales Cañeros (CAI) (existentes hasta hoy), acercamiento a la forma pre-existente antes de 1959, con productores integrados bajo la conducción de la industria procesadora. A partir de 1983 se disuelven las empresas consolidadas para el surgimiento de las empresas de segundo grado o Uniones de Empresas en la Agricultura no cañera. Algunas de estas incorporaron el acopio para mejorar la gestión empresarial. Ocurrió integración de las empresas productoras con las plantas de beneficio, como en la avicultura, porcicultura, el arroz y citricultura. Esto simplificó las relaciones entre orígenes y destinos de las producciones, en tanto vinculó de forma más directa productores y comercializadores, permaneciendo algunas producciones ligadas al MINAL.

Durante los años de 1980 surgió un mercado libre campesino (en que no participaba el sector estatal) como estimulo a la producción privada y alternativa al sistema de distribución racionada. Pero surgieron problemas como elevación de los precios, control de ofertas, abusos de los intermediarios. Debido a esto se limitó el acceso solamente a campesinos asociados a Cooperativas de Crédito y Servicios (CCS) (campesinos privados) y 
Cooperativas de Producción Agropecuarias (CPA). Fue cerrado en 1987, cuando se crearon los Mercados Estatales Paralelos, con oferta de los productos excedentes de los compromisos estatales, con precios más elevados y regulados.

En 1988 la actividad de acopio se integra en la Unión Nacional de Acopio, constituida por 14 empresas de Acopio, formando parte de MINAGRI. En esta segunda mitad de los ochenta las empresas de acopio registraran una baja eficiencia y no contribuyeron para estimular la producción.

De modo general sobre el período el autor destaca que "en esta fase, ha prevalecido el monopolio estatal, con precios de acopio preestablecidos y poco estimulantes, dejando poco o ningún espacio a la utilización del mercado como herramienta" (GONZÁLEZ, 2013, p.35). El costo social de la ineficiencia se reflejó en la falta de oferta y como consecuencia en los altos precios al consumidor en el mercado libre y en el informal, estimulado por.

La crisis en los años noventa motivó cambios en el sector con destaque para la creación del Mercado Libre Agropecuario en octubre de 1994, al cual podrían acceder productores estatales, cooperados o privados (una vez cumplidos los compromisos con los contratos con el Estado). Hubo cambios en la tenencia de tierras y favorecimiento de la forma cooperativa de producción. Las actividades de acopio en general fueron limitadas a escalas locales y se crearon nuevos canales con mantenimiento de la regulación estatal.

La reapertura del Mercado Libre agropecuario deflacionó los precios del mercado subterráneo. Surgieron nuevos espacios de comercialización como: ferias agropecuarias, mercado de tiendas en divisas, ventas en huertos y organopónicos, puntos de ventas de las CPA y CCS. Algunas producciones como papa, café, cacao, leche, huevo, carne vacuna y miel de abeja no son permitidas en el mercado libre, manteniéndose bajo control estatal.

A pesar de la apertura de un mercado libre, este se mantuvo sometido a la oferta, dado a los elevados compromisos de las UBPC y CPA de más de 70 a 80\% de algunas producciones, a precios establecidos por el mercado de acopio, bien más bajos que el mercado libre. Entre 1994 y 1997 se observa un descenso del precio, estabilidad a partir de 1998 y ascenso a partir del nuevo siglo. El autor destaca que la producción se encuentra limitada por factores como los altos niveles de regulaciones, la dualidad monetaria y falta de oferta por parte del sector cooperativo (CPA y UBPC) y estatal. Es resaltado el papel necesario del intermediario, pero también su conflicto de intereses que incide en los precios para el consumidor. 
Sobre el período entre 2001 y 2010 el autor realiza un análisis de los precios, destacando la inestabilidad de la producción nacional, con descenso en 2004, que llevó a la reducción de la oferta y al aumento de los precios en el mercado libre. Apunta la contradicción en disminución de la oferta y del precio de los productos cárnicos a partir de 2004.

En el período de 2005 a 2009, se destacó el descenso de los precios en 2009, ante la fijación de precios topados en mercado libre (debido el paso de huracanes en octubre de 2008). La implementación de requisitos y autorizaciones, junto con el cierre de puestos de ventas en los barrios y no realización de ferias agropecuarias formaron barreras restrictivas al flujo contínuo en el abastecimiento.

En 2010 se trasladó la actividad de acopio de la provincia y Ciudad de La Habana al MINIC, lo que el autor considera un camino ya hecho y no apropiado.

Como últimas consideraciones del capítulo establece la comparación de los precios de acopio con los precios minoristas en el Mercado Agropecuario Estatal (MAE) y Mercado Libre, lo que favorece la Empresa Estatal de Acopio (desde un 20\% hasta un 65\% queda para los comercializadores). El autor considera que los precios del mercado libre son más atractivos para los productores. De tal modo el precio del acopio estatal debía equipararse al del mercado libre y del mercado internacional. Las cuestiones citadas, además la falta de un mercado de insumos y maquinaria, distanciaron al productor de un sentido de pertenencia y trajeron implícito el no reconocimiento de la existencia real del mercado.

El principal problema está en la producción y no en la circulación, pero esta debería avanzar con base en un enfoque sistémico, con la mejora de la industria de beneficio, procesamiento y conservación (superar problemas como falta de capacidad, envases, obsolescencia). Siendo estos retos fundamentales para la cuestión de produccióncomercialización agropecuaria.

En el tercero capítulo "Medidas implementadas e incrementos en la producción de alimentos (2007-2010)" se resaltan los principales cambios realizados recientemente, relacionados al incremento de precios de algunos productos agropecuarios, la distribución de tierras ociosas en usufructo y el control de la actividad de acopio y comercialización.

El incremento de precios ocurrió en productos como la leche y la carne. Para la leche se pagó una proporción en CUC por litro entregado, lo que recuperó la producción, pero disminuyó algunas entregas a la industria láctea afectando la producción de mantequilla, suero y otros derivados. Para la carne, el incremento de 0,18 Pesos Convertibles (CUC) por 
cada 100 libras, no ha sido suficiente para estimular más los productores. Las CCS producen animales con mejor peso (entre 450-500 KG, por encima de la media nacional que en 2009 fue $328 \mathrm{KG})$. Los pagos en CUC estimulan la capacidad de compra en tiendas de insumos agropecuarios recién creadas (en 70 municipios, de los 168 existentes), todavía estas tienen poco surtido y precios elevados. La cuestión de gran diferencia del precio de Acopio Estatal comparado con los de MAE y Mercado libre permanece.

La distribución de tierras ociosas existentes fue implementada por el Decreto-Ley de 25 de julio de 2008, implementado, a través del Reglamento Decreto-Ley 282 de agosto de 2008 .

Ségun datos del Anuario Estadístico de Cuba (2008) a finales de 2007 la superficie no cultivada en Cuba era de

“3631 mil hectáreas (de ellas 2398 mil ha de pastos naturales, con baja carga de animal/ha y 1232 mil ha ociosas). La superficie agrícola no cultivada representa $54,8 \%$ del área agrícola del país, mientras que las tierras ociosas 18,6\% del área agrícola. El Ministerio de la Agricultura registra 1758962 ha de tierras ociosas." (GONZÁLEZ, 2013, p.57)

Dado el escenario de tierras ociosas y de falta de producción agrícola se consideró que la medida fuera tomada ya tardíamente. A finales de 2009 fueron entregadas cerca de $52 \%$ de tierra ociosa, de las cuales $35 \%$ se estimó estar sembrada, beneficiando más de 100.000 personas.

Entre algunos problemas no totalmente esclarecidos o tomados en cuenta por el decreto ley están: a)El tiempo de diez años de usufructo (aún que renovables) sin distinción del tipo de cultivo. b) En caso de cierre del contrato las bienhechurías pueden ser resarcidas con excepción de la vivienda, lo que desestimula la permanencia en la tierra y no ayuda en la recampesinación de los espacios rurales cubanos. c) No están esclarecidos las proporciones de los contratos para el acopio estatal, en general los altos compromisos con esta forma de venta no estimulan el aumento de la producción. d) La burocracia y demora del proceso que pude llegar entre 98 a 128 días. Estas son cuestiones que interfieren en el sentido de pertenencia y llevan al campesino a invertir menos en la finca.

Para allá de la entrega de tierras el autor destaca como medidas necesarias para ampliar la producción: la consolidación de un mercado de insumos con precios asequibles, libertad para contratar fuerza de trabajo, financiamiento y asistencia técnica adecuada, poder de decisión sobre la producción y la venta.

Tales medidas contribuirían para la realización de la propiedad, que para el autor seria "el derecho del productor de poder decidir, qué debe producir, a quién vender lo producido, 
a qué precio, el acudir a un mercado de insumo para comprar los medios necesarios y en el momento oportuno, con el objetivo de lograr el cierre exitoso del ciclo productivo." (GONZÁLEZ, 2013, p.61)

Esto sería un punto aún a cambiar, disminuyendo el control de la actividad de acopio y comercialización a favor de la posibilidad de realización de la propiedad, una vez que "la forma de propiedad determina el carácter del nexo que une al productor con los medios de producción, no solo en la fase de la producción material sino también en las relaciones de distribución cambio y consumo" (GONZÁLEZ, 2013, p.62). Señala como ejemplo la organización de cooperativa de segundo grado para comercialización de la producción, para que la mayor parte de las ganancias puedan retornar al productor y ser reinvertida en la producción.

A finales del capítulo trata de las nuevas formas de descentralización a través de las delegaciones municipales de agricultura (que tratan de la entrega de tierras y velan por las masas ganaderas), con la definición de tres escenarios: agricultura urbana, suburbana (10 km de la ciudad) y polos productivos o convencionales, con experiencias iniciadas en 17 municipios. Siendo estos en la actualidad la forma de división principal de la actividad agrícola.

A modo de conclusión del capítulo el autor refuerza la necesidad del trabajo bajo un enfoque sistémico, el debate profundo sobre las formas de propiedad, el reconocimiento del papel del mercado, los problemas de falta de liquidez en divisa y la necesidad de liberación de las fuerzas productivas.

El cuarto capítulo es intitulado "Producción Agrícola. Lineamientos de la Política Económica y Social del Partido y la Revolución”. En este se hace una comparación de diversos puntos del Proyecto de Lineamentos de la Política Económica del Partido y la Revolución con los Lineamentos aprobados para analizar las condiciones de realización de los elementos considerados fundamentales para el desarrollo de las fuerzas productivas en el nuevo escenario político y económico.

Con los cambios ocurridos, como la entrega de tierras ociosas, surgió un nuevo escenario en el cual se pasa a un predominio de la pequeña y media propiedad, en contraposición a la gran propiedad estatal. En 2007 la tenencia de tierra estatal era de 35,8\% y no estatal de $64,2 \%$, ya en 2011-2012 la tenencia de tierra estatal pasa a 17,0\% y no estatal a $83,0 \%$. 
La ocurrencia de resultados insatisfactorios ante esta medida, como la caída de la producción en 2010, lleva al autor a acotar tres aspectos que cree influenciar el detenimiento de las fuerzas productivas y la baja producción alimentaria. Estos serían: la no realización de la propiedad; el no reconocimiento del papel real del mercado; la ausencia de un enfoque sistémico para el análisis de la cadena producción-comercializacón.

Como propuestas para resolución de estos aspectos González (2013) destaca cinco elementos:

1. Consolidación de un mercado de insumos y bienes de producción con precios asequibles.

2. Libertad para el productor decidir sobre o qué producir y cómo vender de acuerdo con la dinámica del mercado.

3. Diversificar las formas de comercialización con: cooperativas de segundo grado; comercialización individual; ampliación de puntos de venta minorista.

4. Libertad para contratar fuerza de trabajo laboral.

5. Financiamiento y asistencia técnica a las personas que acceden a tierras ociosas.

Sobre el primer punto, los lineamentos aprobados trazan caminos para la consolidación de un mercado de insumos y bienes.

En relación con la libertad de escoger del productor acerca de qué producir, cómo y a quién vender, el autor considera que hubo limitaciones y cambios introducidos en los lineamentos aprobados en comparación con el proyecto, lo cual limita la autonomía del productor en cuestiones fundamentales como: definición de precios, limites a participación de intermediarios, mantenimiento de una gran centralización de decisiones relativas a la agricultura y falta de especificidad de puntos importantes como la autonomía de gestión de las cooperativas.

En relación a la comercialización, con excepción del punto que limita la participación de intermediarios, se considera que están abiertas posibilidades para una mayor diversificación de sus formas.

Sobre la contratación de fuerza laboral tanto los lineamentos aprobados como las resoluciones 32 y 33/2010 de octubre de 2010 del Ministerio del Trabajo que aprobaran la actividad de trabajador agropecuario por cuenta propia, permitiendo a las CPA, CCS y el privado a contratar la fuerza de trabajo que necesite. 
Acerca del último punto se consideró que en los lineamentos aprobados las referencias a asistencia técnica, principalmente para las personas beneficiadas pelo Decreto-ley 259, son insuficientes.

Como consideraciones finales del capítulo el autor destaca el punto que en los lineamentos se "primará la planificación y no el mercado" y concluye que "el problema no consiste en más planificación y menos mercado y viceversa, sino en la complementariedad que debe existir entre ambos elementos, es decir en las dos partes que forman un todo, y el hecho de tener bien definido en última instancia qué parte es la que determina." (GONZÁLEZ, 2013, p.91).

El mercado tiene su existencia real donde hay relaciones monetario-mercantiles, sus mecanismos ayudan a determinar precios, distribución y mejorar la eficiencia productiva en muchos reglones económicos. El papel del Estado debía ser regular el mercado de forma indirecta, con impuestos e incrementos de ofertas necesarias y lograr la equidad y estabilidad sociales.

Considerando los elementos necesarios para la realización de la propiedad, el proyecto se presentó como un documento más avanzado que los lineamentos aprobados. Todavía es fundamental mejorar la comprensión del papel de complementariedad entre mercado y la planificación. También el enfoque sistémico que no debe ser limitado al sector agropecuario, sino al conjunto de la economía a fin de abarcar la complejidad exigida al tratarse del sistema económico.

En el quinto capítulo llamado "La propiedad en la economía cubana. Modelo agrícola y formas de propiedad" González introduce el tema destacando que en Cuba el alto grado de estatización realizado después de la Revolución ciertamente fue uno de los más grandes en todos los países que conformaran el sistema socialista en el mundo. Esto trajo problemas como un elevado nivel de centralización, demasiada burocratización, limitación de las acciones individuales y autonomía de los productores. Recurre al pensamiento de Marx, Engels y Martí para justificar sus proposiciones.

Recuerda que Engels ya alertaba que la propiedad estatal de las fuerzas productivas no eran solución definitiva para el conflicto de clases, pero una posible forma transitoria, junto a otras formas de propiedad colectiva y procesos de cooperación. Apuntaba la cuestión del alquiler como importante para delimitar la propiedad jurídica del Estado y la propiedad económica del productor. 
José Martí a su vez, afirmaba que en la búsqueda de la equidad y justicia social, debería haber un equilibrio entre la propiedad estatal y la libertad individual del productor, advocando sobre la importancia de la existencia de muchos pequeños propietarios en las comunidades y sobre los riesgos del Estado paternalista.

Para González (2013) la cuestión de las formas de propiedad en la economía cubana es un punto central a ser más debatido en el ciclo de producción-distribución-cambio en el sector agropecuario. De este modo, hace un recorrido por las formas de propiedad en Cuba a lo largo de la historia, con propósito de apuntar posibles soluciones para el caso en la actualidad.

La primera periodización es de la agricultura cubana a lo largo de cuatro siglos, entre 1510 a 1898. A partir de 1590 se inicia el desarrollo de la industria azucarera, pero sin base en el latifundio. Las grandes haciendas ganaderas formadas al principio del período también se fueron deshaciendo en propiedades menores con el crecimiento de la población. A finales del siglo XIX las propiedades tenían una media de 57 hectáreas, con predominio de hasta 13 hectáreas que ocupaban cerca del $50 \%$ de las áreas agrícolas del país. Cuba era un país de pequeños y medianos productores, dedicados a los cultivos de exportación como azúcar, café y ganado, pero también con una amplia diversificación agrícola para garantizar el autoabastecimiento de la población.

El período de la República fue marcado por las intervenciones norteamericanas que crearon condiciones para la entrada de capital extranjero, principalmente de los Estados Unidos. Para el sector agrícola esto representó la posibilidad de créditos para los grandes hacendados, que pasaron también a ocupar tierras en la parte central y oriental del país, las que adquirían a bajos precios. Este proceso fue destruyendo las pequeñas y medianas propiedades, en 1934, 40\% de los cubanos ya habían perdido sus tierras. En 1959, 9,4\% de los propietarios tenían cerca de $73,3 \%$ de las áreas. La agricultura cubana se tornó latifundista, especializada en los monocultivos para agroexportación. Con la concentración de tierras se perdió diversidad, aumentaron las desigualdades y se creó un escenario de dependencia de importaciones de alimentos y vulnerabilidad alimentaria.

Al triunfo de la Revolución en 1959, con la Primera y Segunda Leyes de Reforma Agraria, fueron entregadas tierras a quienes las trabajaban, abarcando a cerca de 100 mil campesinos y pasaron cerca de $70 \%$ de las tierras a manos del Estado. Estas últimas fueron administradas de forma planificada, creándose las granjas del pueblo en los latifundios 
ganaderos y cooperativas en las áreas cañeras. Pero, en 1962, las cañeras fueron transformadas también en granjas del pueblo, bajo un mayor control estatal.

El modelo privilegió las grandes propiedades estatales sobredimensionadas, lo que en la práctica contribuyó a la disminución del campesinado. Aunque hubo una mayor diversificación, la orientación del monocultivo para la exportación se mantuvo, complementada por una gran incorporación de las prácticas de la "Revolución Verde" con apoyo externo del campo socialista de la URSS. El alto gasto con insumos por área sin obtención de los resultados esperados condujo a una gran proporción de empresas no rentables. En general las formas cooperativas como las de Crédito y Servicios (CCS) (campesinos privados) y las de Producción Agropecuarias (CPA), aún con sus mejores resultados, no fueron las formas más incentivadas.

Consideramos el abordaje del autor sobre esto período poco extenso para esclarecer su complejidad, siendo comprensible su opción por privilegiar su atención hacia los cambios más recientes del período pos-crisis de los noventa. Una mejor mirada sobre estos procesos de formas de propiedad puede ser apreciada en obras como las de Paz (2009) y Sorzano et. al (2013).

Sobre el período entre 1993 a 2009 el autor apunta que el deterioro de la eficiencia en la economía agrícola cubana a mediados de la década de los ochenta ya se percibía. Sumado a esto los efectos de la caída del campo socialista conllevó a la crisis económica de la década de los noventa, principalmente para el sector agropecuario.

Entre las medidas implementadas para enfrentar la situación gran parte de las empresas agrícolas estatales fueron subdivididas en Unidades Básicas de Producción Cooperativa (UBPC), se entregaron tierras en usufructo, se reabrió el mercado agropecuario de venta minoristas. De este modo, junto a las CCS y CPA el enfoque en el trabajo cooperativo pasó a ser predominante en el sistema agrícola cubano. Entretanto, las restricciones y limitaciones impuestas a las UBPC hacen que estas sean miradas como formas "transfiguradas de empresa estatal".

Actualmente, las entidades productivas del sector agropecuario cubano son las UBPC, CPA, CCS, privado y estatal. Estas se corresponden con las diferentes formas de propiedad. Es interesante que el sector más productivo sean las CCS y campesinos privados que trabajando en el 24,4\% de las tierras, producen $57 \%$ de los alimentos del país.

Para el autor estos resultados son asociados a su conservación del derecho de propiedad. Lo que debe ser observado para la organización de las tierras que están siendo 
entregadas en usufructo. Esto, manteniendo el cobro del arrendamiento al Estado como forma de garantizar la propiedad jurídica de la nación y la propiedad económica al productor, con su autonomía sobre escoger las formas de explotación de la tierra. Asimismo, garantizar la asistencia técnica necesaria para valorizar la sabiduría campesina sumada a los avances técnico-científicos del campo agropecuario, a fin de lograr la recuperación necesaria de la producción alimentaria en el país.

En los capítulos siguientes el autor establece algunos paralelos de las experiencias ya descritas del sector agropecuario cubano, con los cambios vividos en la agricultura en Vietnam y la cuestión de la producción sucroalcoholera en Brasil.

En el sexto capítulo "La agricultura en Vietnam. Experiencias" el autor traza un breve paralelo entre los cuadros físicos y sociales de Cuba y Vietnam y destaca los cambios ocurridos en el último a partir de 1986 que llevaron al establecimiento de una economía socialista de mercado.

El autor se refiere al crecimiento en el Producto Interno Bruto (PIB) y al volumen de exportaciones realizados por el Vietnam y apunta algunos cambios en la política agrícola: el anexo de las actividades forestales y de la pesca al sector agrícola; mayor integración y tecnificación; apertura a inversiones extranjeras; cambios en el papel del Ministerio de la Agricultura al asumir funciones macro-directivas y no más de organización de la producción.

Sobre la política de tierras fueran entregadas tierras en usufructo, con plazo delimitado de acuerdo con el tipo de cultivo, sin pago al Gobierno. Además, contratos sobre las producciones, bienhechurías, construcción de viviendas y cuestiones hereditarias. Políticas de inversiones del Gobierno en obras de riego, drenaje y estimulación a variedades de cultivo y razas de animales certificados. Política de crédito y liberalización del mercado de la producción agrícola e insumos.

Contrapuesto a los ejemplos del Vietnam el autor explica la complejidad y burocracia del proceso de entrega de tierras ociosas en usufructo en Cuba. Subraya el reconocimiento del papel del mercado en la economía vietnamita, con el mantenimiento de los medios de producción considerados fundamentales. Y la necesidad de comprensión del papel del mercado con la planificación para la realización plena de la propiedad en la economía cubana.

El capítulo sétimo trata de "La agroindustria sucroalcoholera en Brasil. Una alternativa". Hace un recorrido por la historia de esta producción en el país desde la creación del Instituto del Azúcar y del Alcohol (IAA) en 1933, hasta la implementación del Programa Nacional del Alcohol (Pro-alcohol) en los años 1970. A pesar de los incentivos la producción 
del alcohol no era tan competitiva como el petróleo, a finales del régimen militar se retiró los subsidios y en 1990 se eliminó el IAA.

Al comienzo del siglo XXI esta producción entra en una nueva fase frente a la demanda de agrocombustibles, la producción de automóviles flex-fuel. Mejoras en la tecnología de producción, así como el alto nivel de productividad de la caña para la producción de combustible comparado a otros vegetales, hace que la producción de agrocombustibles en Brasil pase a ser más competitiva. Subraya las inversiones en estudios para aprovechar toda la biomasa, sea para producir alcohol de segunda generación (bagazo y paja) o hacer la gasificación de la biomasa. Resalta el papel del Gobierno brasileño con incentivos para formación de Arreglo Productivo Local del Alcohol (APLA), trayendo datos principales de la producción en el país.

Acerca de la realidad cubana es destacado el escenario del bajo uso de agrocombustibles y los cambios recientes entre 2001 a 2004 con el cierre de varios centrales azucareros y redimensionamiento del sector. El autor señala de la importancia de la transformación de la actual agroindustria azucarera en una agroindustria bioenergética de la caña de azúcar, con incremento en la producción de alcohol, como forma de minimizar la alta dependencia de combustibles fósiles, reducir las emisiones de gases del efecto invernadero, disminuir importaciones y ampliar las exportaciones. Para esto el ejemplo brasileño es una referencia interesante.

A pesar de la referencia para la cuestión energética en el siglo XXI, consideramos que el enfoque sobre los agrocombustibles es poco critico, por no tratar del problema de su competición con el uso de la tierra para la producción alimentaria en Brasil y las posibles implicaciones de esto en Cuba.

En el último capítulo "Producción nacional de alimentos. Medidas implementadas y Lineamentos de la Política Económica del Partido y de la Revolución” el autor retomada los debates sobre los problemas identificados en la cadena de producción-distribución-cambio del sector agropecuario y enfoca el análisis en la producción y comercialización agrícola en el año 2011. Entre los principales problemas observados están las contradicciones del aumento de la producción agrícola en relación al año anterior, pese a la reducción de las ofertas-ventas, que generaron un incremento en los precios. Subraya la necesidad de trabajar frente a problemas previsibles como las sequías, con el objetivo de crear reservas de alimentos como granos; integrar en la producción cañera el aprovechamiento de productos colaterales para la alimentación del ganado. 
Cuestiona la dilatación en la implementación de los Lineamientos aprobados en el VI Congreso del PCC para resolver problemas fundamentales como: la demora y burocracia en la entrega de tierras en usufructo; la insuficiencia del mercado de insumos y medios de trabajos a precios elevados; la necesidad de modificaciones en el Decreto-ley 259 para cambiar puntos de incertidumbres que no favorecían la permanencia en el campo; falta de medidas de descentralización del mercado y monopolio del sistema de acopio estatal; los bajos precios pagados al productor, inclusive por productos que sustituyen importaciones y aún son pagados a precios elevados por productos importados; dilación en la entrega de créditos y asistencia técnica.

El autor concluye reafirmando que la realización de la propiedad, el reconocimiento de la existencia del mercado y su complementariedad con la planificación y el enfoque sistémico para la concepción y implementación de medidas, siguen siendo son retos para la mejoría de los resultados del sector agropecuario cubano.

\section{CONSIDERACIONES FINALES}

Al final de su trabajo es presentado un epílogo con tres partes. La primera trata de "Teoria y práctica de los Lineamentos de la Política Económica y Social del Partido y la Revolución" donde hace un recorrido general sobre el proceso social de construcción del proyecto de lineamentos, que involucraron desde 2007 más de 200.000 reuniones con amplia participación popular, resultando en más de 1.300 .000 planteamientos, que posteriormente fueron rediscutidos, resumidos y relacionados en los 313 lineamentos aprobados en el VI Congreso del PCC en abril de 2011. El autor apunta que además de la amplia participación, la metodología utilizada de una tormenta de ideas fue necesaria, pero insuficiente, destacando que el aporte a partir de un enfoque sistémico de las Ciencias Sociales tendría importancia para incorporar soluciones mejor interrelacionadas, con estrategias más claras para alcanzar las metas deseadas. Considerado esto, el autor destaca su ejemplo para un abordaje sistémico de la política agrícola.

Las otras dos partes del epílogo hacen referencia a los últimos cambios en la entrega de tierras en usufructo, con la implementación del Decreto-ley 300 que garantizó la cuestión de la vivienda y eliminó el cobro de impuesto por el uso de la tierra. Al final trata del nuevo reglamento publicado en 2012 para las UBPC que para él no resolvió el problema fundamental de ampliación de la autonomía de estas unidades productivas. 
La lectura de la obra de González puede sorprender por sus puntos de vista sobre la necesidad y formas para ampliar las fuerzas productivas en el sector agropecuario cubano. $\mathrm{Su}$ debate de la complementariedad entre mercado y planificación, aún no sea unánime en la visión política, viene siendo recurrente entre estudiosos del sector en Cuba. Lo que pasa es que las difíciles condiciones para Cuba en mantener la opción socialista después de la caída de este campo en la Europa Oriental y frente al recrudecimiento del bloqueo económico implementado por los Estados Unidos son condiciones únicas en el mundo y generaron mucha complejidad para el desarrollo económico del país y para comprensión de estos procesos desde afuera.

De este modo, observamos que las opiniones expresadas por el autor surgen en un contexto de cambios en los últimos años, como la apertura del país para las inversiones extranjeras y el turismo, la ampliación de intercambios académicos, incluso con países como Brasil. Lo que abre nuevas perspectivas para pensar posibles caminos de reestructuración del sector agropecuario que minimice la histórica vulnerabilidad alimentaria existente en el país. Así, analizar su obra contribuye para comprender como se desarrolla el debate académico cubano sobre los cambios vividos en el proceso revolucionario y los ajustes necesarios para seguir en la actualidad la opción de la equidad y justicia sociales.

\section{REFERENCIAS}

GONZÁLEZ, A. N. El modelo agrícola y los lineamentos de la política económica y social en Cuba. Editorial de Ciencias Sociales: La Habana. 2013. 198 p.

SORZANO, A. H.; SOUSA, R. G.; FUNDORA, E. M. Cuba: modificaciones en la tenencia de la tierra y el desarrollo de la agricultura urbana: avances en seguridad alimentaria. La Habana: FAO/Facultad de Geografía/Universidad de La Habana, 2013.

PAZ, J. V. Los procesos de organización agraria en Cuba 1959 - 2006. Fundación Antonio Nuñez Jiménez de la Naturaleza y el Hombre. La Habana. 2009. 